\title{
Predictive ability of problem-solving efficacy sources on mathematics achievement
}

\author{
Januard D. Dagdag, Noel A. Palapuz, Nikka A. Calimag
}

College of Education, Isabela State University, Roxas, Isabela, Philippines

\begin{tabular}{l} 
Article Info \\
\hline Article history: \\
Received Dec 30, 2020 \\
Revised Aug 5, 2021 \\
Accepted Sep 9, 2021 \\
\hline
\end{tabular}

\section{Keywords:}

Efficacy

Mastery experience

Mathematics achievement

social persuasion

Problem-solving

Vicarious experience

\begin{abstract}
This study examined the relationship between mathematics achievement and mathematics problem-solving efficacy sources. A cluster sample of 123 first year prospective teachers of a Philippine higher education institution responded to a 30-item problem-solving efficacy scales and took the teachermade tests in Mathematics in the Modern World course; namely, NonRoutine Problem Solving and Natures and Numbers Pattern Tracing (NRPSNNPT), Math Language and Symbols (MLS), and Data Management (DM). The research data was analyzed using Descriptive statistics, Pearson-r and Standard Multiple Regression. On the average, the respondents had satisfactory mathematics achievement. They reported a high level of social persuasion and somatic response and a low level of vicarious experience and mastery experience in mathematics problem-solving. Vicarious experience was directly associated with mastery experience while social persuasion and mastery experience were both inversely related to somatic responses. Among the four problem-solving efficacy sources, only social persuasion significantly predicted mathematics achievement specifically in the areas of NRPS-NNPT, MLS, and DM. Thus, becoming a trusted voice of encouragement and designing a persuasive and optimistic learning environment are highly recommended roles of schools to facilitate students' mathematics achievement.
\end{abstract}

This is an open access article under the CC BY-SA license.

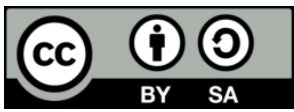

Corresponding Author:

Januard D. Dagdag

College of Education

Isabela State University

Roxas, Isabela, Philippines

Email: januard.d.dagdag@isu.edu.ph

\section{INTRODUCTION}

One of the most important competencies students must acquire today to increase their opportunities and potentials for success, is mathematical knowledge and skills [1]. Ironically, the achievements of typical students in college mathematics are not satisfactory, if not below the standards [2], [3]. Several investigations have established that affective characteristics are important factors that affect achievement [4]-[6] particularly, mathematics achievement [7]-[12]. One of these affective characteristics is self-efficacy belief [5], [7], [9], [10], [13], [14].

Self-efficacy comes from four main sources based on literature: mastery experience, vicarious experience, social persuasion, and somatic responses. Mastery experience is the result of one's previous experience that allows students to apply concepts they have already learned [12] and is the strongest source of self-efficacy [5]. Vicarious experience is seeing a role model who is doing the related task successfully and who has positive or negative effect on one's self-efficacy [13]. Social persuasion is mainly the feedback, negative or positive, to the performance of an individual from the people around [12]; and somatic responses 
are basically the mood of the individual in performing and completing the task such that doing the task while experiencing stress and anxiety may result to incompetency and very low performance [5].

According to Bandura [5], self-efficacy beliefs pervasively influence people in achieving their goals, the amount of effort they apply in the task, and their perseverance in facing difficulties and stress. Mastery experiences, according to other studies, are also shown to be significantly related to some self-efficacy sources [15], [16]. Most studies show the variations on the level of significance of self-efficacy and mastery experiences [7], [12], [15], [16]. Similarly, several studies assert different levels of significance between psychological states and vicarious experiences [7], [17]-[19]. On the other hand, a study affirms that selfefficacy and vicarious experiences are insignificantly related [18].

Most studies assert that the strongest predictor of mathematics achievement is mastery experiences, followed by social persuasions, physiological states, and the weakest predictor is vicarious experiences [12], [19]-[21]. On the other hand, there are some studies that argue social persuasion has greater association with mathematics achievement than the three [17], [22], [23]; mathematics performance and vicarious experiences have no relationship [17], [22]; and the relationships of psychological states with academic achievement and mathematics achievement vary i.e. while some studies show that physiological states are significant factors of achievement [16], [17], [24], [25], others assert that it has low and insignificant effect [19], [24], [26]-[28].

Clearly, there are inconsistent results among studies that examined the relations between the four self-efficacy sources and between self-efficacy and mathematics achievement. The results vary depending on cultural differences and educational level [15], [16]. Most studies on these constructs have focused on selfefficacy and academic achievement among children and high school students abroad. Little is known today about the mathematics problem-solving efficacy and the mathematics achievement of Filipino prospective teachers particularly in Mathematics in the Modern World (MMW) course.

Mathematics problem-solving efficacy is a specific type of self-efficacy. It particularly refers to one's perceived ability to solve a mathematical problem or task. Problem-solving efficacy is also determined by social persuasion, somatic responses, vicarious experiences, and mastery experiences [23]. Hence, the problem-solving efficacy of prospective teachers reflects their confidence in their ability to execute the skills necessary for learning their current mathematics course which is MMW.

MMW is a 3-unit general education course offered among first year students in the Philippines. As part of the CHED K-12 transition program for 2016-2021, the course deals with mathematics as an exploration of patterns, application of inductive and deductive reasoning, and a tool in daily life. In the current study, mathematics achievement refers to the test (percent) scores of the students in the three main lessons of MMW; namely, Non-Routine Problem-Solving and Nature and Number Patterns Tracing (NRPS \& NNPT), Mathematical Language and Symbols (MLS), and Data Management (DM).

Hence, the current study aims to examine the relations between the problem-solving efficacy sources and the mathematics achievement of Filipino prospective teachers. Specifically, this study sought answers to the following questions: i) What is the mathematics achievement of the prospective teachers?; ii) What are their problem-solving efficacy sources?; iii) Is there a significant relationship between and among their mastery experiences, vicarious experiences, social persuasions, and somatic responses?; and iv) Which of the problem-solving efficacy sources can significantly predict mathematics achievement?

It is hoped that this study can further the understanding of the importance of self-efficacy on Filipino prospective teachers' success in college mathematics, and provide important discussions with the abovementioned contradicting literature findings. As future teachers, their acquisition of mathematical competencies is highly important and their problem-solving efficacy might affect their mathematics achievement. Therefore, this study can help teacher educators especially mathematics teachers to integrate in the instructional planning and implementation the degree of importance of each problem-solving efficacy source on mathematics performance.

\section{RESEARCH METHOD}

\subsection{Research design}

This study utilized correlational design to assess the relationship between students' mathematics achievements and problem-solving efficacy sources. According to Creswell [29], a correlational design is a non-experimental form of research that uses correlational statistics to describe and measure the degree of relationship between two or more quantitative variables.

\subsection{Participants}

The current study targets all education students enrolled in GEC 03: Mathematics in the Modern World (MMW) in a university during the school year 2019-2020. To control the effect of extraneous variables, a cluster sampling was done to select one higher education institution where students were taught 
in the said subject by the same teacher. All the 123 freshmen college of education students in this higher education institution served as the participants. There were 36 male students and 87 female students that sectioned heterogeneously into 43, 44, and 36 students. They were taught by a single teacher in the said mathematics subject.

\subsection{Research instruments}

The study adopted the 5-point Likert scales developed through an exploratory factor analysis by Dagdag, et al. [23] to measure the underlying construct of students' problem-solving efficacy in mathematics. This instrument was chosen as it is normalized in the context of the participants [23]. The 30item instrument has four component factors, namely: social persuasions (10 items), somatic/physiological responses (10 items), vicarious experiences (five items), and mastery experiences (five items). The number of items in each component varies as EFA is concerned on the quality of factor loadings i.e., retaining at least three high (>.40) factor loadings per component [23], [30], [31]. Generally, the components account satisfactorily for $58.19 \%$ of the overall variance and their Cronbach reliability coefficients range from acceptable, alpha $=.717$, to highly reliable, alpha $=.925$ [31]. Based on the current research data, the Cronbach reliability coefficients of the four scales were $.874, .837, .873$, and .764 , respectively.

Three two-hour teacher-made tests with tables of specifications (whose features are shown in Table 1) were developed to measure the students' achievements in mathematics particularly in Non-Routine Problem-Solving (NRPS) and Nature and Number Patterns Tracing (NNPT), Mathematical Language and Symbols (MLS), and Data Management (DM).

The problem-solving tests worth five points each. Merit points for the multiple-choice (which ranges from 1 to 3 ) depend on the item difficulty level ( 2 to 3 points for items that involve solving) while the MLS tests were practical tests in logic. The content validity of these tests was reviewed and evaluated by the faculty, the Dean of the College of Education, and the Academic and Related Affairs Director of the campus.

Table 1. Teacher-made tests used to measure mathematics achievement

\begin{tabular}{clccl}
\hline Test & \multicolumn{1}{c}{ Content/Competency } & No. of items & No. of points & \multicolumn{1}{c}{ Test nature } \\
\hline I & Solving non-routine problems & 5 & 25 & Problem-solving \\
& Tracing patterns in nature and numbers & 18 & 30 & Multiple-choice (Solutions required) \\
II & Mathematical language and symbols & 30 & 100 & $\begin{array}{l}\text { Short answer test } \\
\text { Symbolizing statements }\end{array}$ \\
& & & & $\begin{array}{l}\text { Negating statements } \\
\text { Evaluating truth and falsity of statements }\end{array}$ \\
& & & & Evaluating the validity of arguments \\
III & Data management (Concepts) & 89 & 100 & Multiple-choice \\
\hline
\end{tabular}

\subsection{Data gathering}

The research was conducted upon official approval of the university. A letter asking consent of the students was noted by the dean of college of education. The teacher-made tests were administered at the end of each term of first semester school year 2019-2020, as major examinations of the students (prelim, mid, final) while the problem-solving efficacy scales were administered at the end of the course.

\subsection{Data analysis}

The data gathered was analyzed through the aid of Statistical Packages for Social Sciences version 16 [31]. Frequency and percent were used to gauge the students' distribution by class section. Students' scores in each of the test were converted into percent (student score divided by total possible score multiplied to 100). Descriptive statistics (means and standard deviations) was requested to measure the students' achievements in mathematics and their level of problem-solving efficacy scores. Mathematics achievement (in percent) was categorized as unsatisfactory (50 or below) and satisfactory (above 50) while problemsolving efficacy level was described based on the following guidelines as shown in Table 2.

Table 2. Categorizing self-efficacy level

\begin{tabular}{|c|c|c|c|}
\hline \multirow{2}{*}{ Dimensions } & \multirow{2}{*}{ No. of items } & \multicolumn{2}{|c|}{ Level } \\
\hline & & Low & High \\
\hline Social persuasion & 10 & Below 35 & 35 or above \\
\hline Somatic responses & 10 & Below 35 & 35 or above \\
\hline Vicarious experiences & 5 & Below 17.5 & 17.5 or above \\
\hline Mastery experiences & 5 & Below 17.5 & 17.5 or above \\
\hline Total & 30 & Below 105 & 105 or above \\
\hline
\end{tabular}


Problem-solving efficacy level was classified based on the summation of the four problem-solving efficacy source mean scores i.e., low efficacy for a sum of 11 or below while high efficacy for 12 or above. Data normalization using the technique introduced by Templeton [32] was conducted prior to regression analysis. The continuous variables were converted first as fractional ranks and then the fractional ranks were transformed into normalized continuous variables using idf.normal command of the SPSS. The normality test results after this data transformation technique is shown in Table 3.

Table 3. Normality check

\begin{tabular}{lcccccc}
\hline \multicolumn{1}{c}{ Variables } & \multicolumn{3}{c}{ Kolmogorov-Smirnov ${ }^{\mathrm{a}}$} & \multicolumn{3}{c}{ Shapiro-Wilk } \\
& Statistic & df & Sig. & Statistic & Df & Sig. \\
\hline Normal_RPS & .053 & 120 & $.200^{*}$ & .994 & 120 & .915 \\
Normal_Logic & .034 & 120 & $.200^{*}$ & .995 & 120 & .965 \\
Normal_Statistics & .045 & 120 & $.200^{*}$ & .995 & 120 & .955 \\
Normal_SocialPers & .059 & 120 & $.200^{*}$ & .993 & 120 & .775 \\
Normal_SomaticRes & .066 & 120 & $.200^{*}$ & .991 & 120 & .668 \\
Normal_Vicarious & .054 & 120 & $.200^{*}$ & .990 & 120 & .492 \\
Normal_Mastery & .064 & 120 & $.200^{*}$ & .984 & 120 & .172 \\
\hline
\end{tabular}

Pearson's correlational analysis was conducted to establish the relationship between efficacy sources and to check for multicollinearity i.e., variables that are highly correlated $(r>.80)$. Multicollinearity check showed that the correlation coefficients were all less than .72; suggesting that the assumption was met [31], [33]. Hence, a Standard Multiple Regression analysis was conducted to explore which of the four problem-solving efficacy sources significantly affected mathematics achievements in NRPS \& NNPT, MLS, and DM.

\section{RESULTS}

Table 4 shows students' achievement in mathematics. On the average, the students got 7 in every 10 merits in the mathematics tests. Thus, they had satisfactory achievements in the three mathematics areas. Table 5 shows their levels of self-efficacy sources. As can be gleaned on the table, they indicated that they have a high social persuasion and a somatic response level but they have a low vicarious experience and a mastery experience in mathematics problem-solving.

Table 4. Students' achievement in mathematics

\begin{tabular}{cccl}
\hline Area of mathematics & M & SD & Description \\
\hline NRPS and NNPT & 66.40 & 16.360 & Satisfactory \\
MLS & 71.07 & 10.084 & Satisfactory \\
DM & 67.17 & 12.865 & Satisfactory \\
Overall & 68.21 & 10.601 & Satisfactory \\
\hline
\end{tabular}

Table 5. Students' levels of self-efficacy sources

\begin{tabular}{ccccc}
\hline Dimensions & No. of items & M & SD & Level \\
\hline Social persuasion & 10 & 35.34 & 6.33 & High \\
Somatic responses & 10 & 35.69 & 6.25 & High \\
Vicarious experiences & 5 & 14.45 & 4.37 & Low \\
Mastery experiences & 5 & 16.26 & 3.04 & Low \\
Total efficacy & 30 & 90.37 & 7.50 & Low \\
\hline
\end{tabular}

Table 6 shows the relationship between the four problem-solving efficacy sources. The results affirm that both social persuasion $\left(\mathrm{X}_{2}\right)$ and mastery experience $\left(\mathrm{X}_{4}\right)$ were both significantly associated with somatic responses $\left(\mathrm{X}_{1}\right)$. Social persuasions and mastery experiences significantly explained $50.69 \%$ and $3.84 \%$ of the variance in somatic responses, respectively. Moreover, vicarious experience $\left(\mathrm{X}_{3}\right)$ positively influences mastery experience $\left(\mathrm{X}_{4}\right), r=.553, p<.01$ and shares $30.58 \%$ variance in mastery experience.

The results of the multiple regression analyses as shown in Table 7 indicate that among the four sources of problem-solving efficacy, only social persuasion significantly predicted the students' mathematics achievement in NRPS \& NNPT $(\beta=.378 ; p<.05)$, MLS $(\beta=.464 ; p<.01)$, DM $(\beta=.382 ; p<.01)$, and their overall mathematics achievement $(\beta=.400 ; p<.01)$. 
Table 6. Multiple correlations of the problem-solving efficacy sources

\begin{tabular}{lcccc}
\hline Variables & $\mathrm{X}_{1}$ & $\mathrm{X}_{2}$ & $\mathrm{X}_{3}$ & $\mathrm{X}_{4}$ \\
\hline Social persuasions $\left(\mathrm{X}_{1}\right)$ & 1 & $-.712^{* *}$ & $.260^{* *}$ & $.215^{*}$ \\
Somatic responses $\left(\mathrm{X}_{2}\right)$ & & 1 & -.151 & $-.196^{*}$ \\
$\quad$ Vicarious & & 1 & $.553^{* *}$ \\
Experiences $\left(\mathrm{X}_{3}\right)$ & & & \\
Mastery experiences $\left(\mathrm{X}_{4}\right)$ & & & \\
**means significant at .01 level (two-tailed) & & \\
*means significant at .05 level (two-tailed) &
\end{tabular}

Table 7. Summary of regression analyses for variables predicting mathematics achievements

\begin{tabular}{|c|c|c|c|c|c|c|c|c|c|c|c|c|}
\hline \multirow{2}{*}{ Variable } & \multicolumn{3}{|c|}{ NRPS and NNPT } & \multicolumn{3}{|c|}{ Math language and symbols } & \multicolumn{3}{|c|}{ Data management } & \multicolumn{3}{|c|}{ Overall achievement } \\
\hline & $\mathrm{B}$ & $\mathrm{SE}$ & Beta & B & SE & Beta & $\mathrm{B}$ & SE & Beta & $\mathrm{B}$ & $\mathrm{SE}$ & Beta \\
\hline $\begin{array}{l}\text { Vicarious } \\
\text { experiences }\end{array}$ & 2.160 & 2.250 & .113 & -.875 & 1.336 & -.075 & -.880 & 1.774 & -.058 & -.531 & 1.402 & -.044 \\
\hline $\mathrm{R}^{2}$ & & 0.122 & & & .397 & & & .370 & & & .396 & \\
\hline $\mathrm{F}$ & & $4.04^{* *}$ & & & $5.38^{* *}$ & & & $4.612^{* *}$ & & & $5.332^{* *}$ & \\
\hline
\end{tabular}

**means significant at .01 level

*means significant at .05 level

\section{DISCUSSION}

This study aimed to assess the underlying construct of students' problem-solving efficacy sources to determine the extent to which these sources significantly predict mathematics achievement. Results indicated that social persuasions and mastery experiences negatively associate with somatic responses. Meaning, as social persuasion (or mastery experience) increases, somatic responses decreases. Social persuasion explains around $51 \%$ (while mastery experience explains around 4\%) of the variance in somatic responses. Vicarious experiences and mastery experiences are positively correlated and share $30.58 \%$ of their variance. These patterns of relationships between the four self-efficacy sources do not agree to some extent with previous research. For instance, Capa-Aydin, Kondakci, and Ceylandag [34] argue that mastery experiences have a mediation effect for social persuasion and physiological state but no mediation effect for vicarious experiences. Usher and Pajares [18] assert that vicarious experience is not significantly associated with selfefficacy. Similarly, the result of the current study rebuts the finding of several researches [7], [17]-[19] that vicarious experience is significantly related to somatic response.

Among the four efficacy sources, only social persuasions achieved significant results in explaining achievements in mathematics in the areas of solving non-routine problems and tracing patterns in nature and numbers, logic, and statistics (with beta ranging from .378 to .47). It agrees with studies [17], [22] that the strongest efficacy source predictor of mathematics achievement is praise and feedback. On the other hand, it refutes the claim of previous studies [5], [12], [19], [21] that mastery experience is the best predictor of mathematics performance. The result of the current study also neglects the assertion of several researches [16], [17], [24], [25] that stated somatic response is a significant factor of academic achievement. On the other hand, it affirms the statement of several studies [19], [24], [26]-[28] that somatic response has a low and insignificant effect. Moreover, the current finding highlights that vicarious experience as a mathematics problem-solving efficacy source does not significantly contribute to mathematics achievement [7], [17], [22]

\section{CONCLUSION}

This quantitative research found that social persuasions and mastery experiences are both inversely associated with somatic responses, and among the four efficacy sources indicated in the literature, only social persuasions can significantly predict mathematics achievement in the areas of solving non-routine problems and tracing patterns in nature and numbers, logic, and statistics.

This study contributes to the understanding of the roles of the four mathematics problem-solving efficacy sources on mathematics achievement and guides the decision of schools as to which of the sources should be given more attention and priority to better enhance students' performance in mathematics. The study suggests that maintaining an encouraging learning environment and expanding students' mastery learning opportunities could reduce students' anxiety in solving mathematics problems or tasks. The significance of the predictive ability of social persuasion on mathematics achievement supports that

Predictive ability of problem-solving efficacy sources on mathematics achievement (Januard D. Dagdag) 
becoming a trusted voice of encouragement and designing a persuasive learning environment are highly recommended roles of schools in facilitating the students to attain the necessary competencies of the course. Mathematics teachers should give sincere and timely feedback to students' progress toward a learning goal and encourage them to attribute success and failure in mathematics to the amount of effort they exerted in learning. Nevertheless, the students should be enabled to evaluate their own learning progress against the desired mathematical competencies and outcomes rather than against the learning performance of other students.

However, the variations of the findings with existing studies might be due to the distinct nature of the tests administered to the students and the areas of mathematics involved. Both the NRPS \& NNPT and the DM tests contained multiple-choice type while the MLS test focused on mathematical logic (which cannot be measured validly by multiple-choice). The reliability index of these tests was not established. The study was also limited to a linear regression model between mathematics problem-solving efficacy sources and mathematics achievement.

Future research may wish to replicate the current study using standardized measuring instruments. Other affective variables such as attitude toward mathematics, mathematics anxiety, and motivation may be included through a structural equation model to get a more holistic and realistic measure of the relationship of these variables on mathematics achievement. A qualitative research may be conducted to understand how social persuasion enhances the learning of mathematics and to explore the phenomenology of teachers' engagement in giving feedback and praise in their classroom.

\section{ACKNOWLEDGEMENTS}

The authors would like to acknowledge the Isabela State University for funding the study.

\section{REFERENCES}

[1] National Council of Teachers of Mathematics (NCTM), Principles and Standards for School Mathematics. Reston, VA, 2000.

[2] A. G. Roman, "Curriculum implementation and performance of mathematics education students in one state university in the Philippines," Asian Journal of Multidisciplinary Studies, vol. 2 no. 2, pp 1-8, 2019.

[3] A. D. Patena and B. L. H. Dinglasan, "Students' performance on mathematics departmental examination: Basis for math intervention program," Asian Academic Research Journal of Social Science \& Humanities, vol. 1, no. 14, pp. 255-268, 2013.

[4] B. S. Bloom, Insan nitelikleri ve okulda öğrenme (çev. D. A. Özçelik) (3. Baskı). İstanbul: MEB Yayınları, 1998.

[5] A. Bandura, Self-efficacy: The exercise of control. New York: Freeman, 1997.

[6] D. H. Schunk and B. J. Zimmerman, Self-regulated learning: From teaching to self-reflective practice. Guilford Press, 1998.

[7] E. Yurt, "The predictive power of self-efficacy sources for mathematics achievement," Education and Science, vol. 39, no. 176, pp. 159-169, 2014, doi: 10.15390/EB.2014.3443

[8] M. L. Peters, "Examining the relationships among classroom climate, self-efficacy, and achievement in undergraduate mathematics: A multi-level analysis," International Journal of Science and Mathematics Education, vol. 11, no. 2, pp. 459-480, 2013, doi: 10.1007/s10763-012-9347-y.

[9] P. Chen and B. Zimmerman, "A cross-national comparison study on the accuracy of self-efficacy beliefs of middleschool mathematics students," The Journal of Experimental Education, vol. 75, no. 3, pp. 221- 244, 2007, doi: 10.3200/JEXE.75.3.221-244.

[10] E. Yurt and A. M. Sünbül, "A structural equation model explaining 8th grade students' mathematics achievements," Educational Sciences: Theory \& Practice, vol. 14, no. 4, pp. 1642-1652, 2014.

[11] C. W. Loo and J. L. F. Choy, "Sources of self-efficacy influencing academic performance of engineering students," American Journal of Educational Research, vol. 1, no. 3, pp. 86-92, 2013, doi: 10.12691/education-1-3-4.

[12] E. L. Usher and F. Pajares, "Sources of self-efficacy in mathematics: A validation study," Contemporary Educational Psychology, vol. 34, no. 1, pp. 89-101, 2009, doi: 10.1016/j.cedpsych.2008.09.002.

[13] D. H. Schunk, Learning theories: An educational perspective. Pearson Education, Inc., 2011.

[14] E. L. Usher, "Sources of middle school student's self-efficacy in mathematics a qualitative investigation," American Educational Research Journal, vol. 46, no. 1, pp. 275-314, 2009, doi: 10.3102/0002831208324517.

[15] Y. C. Chen, "Sources of mathematics self-efficacy and predictors of mathematics achievement among seventh- and eighth-grade Taiwanese students," Unpublished Doctoral Dissertation, University of Kentucky, Lexington, Kentucky, UMI No. 3492807, 2010.

[16] A. Arslan, "Predictive power of the sources of primary school students' self-efficacy beliefs on their self-efficacy beliefs for learning and performance," Educational Sciences: Theory \& Practice, vol. 12, no. 3, pp. 1915-1920, 2012 . 
[17] T. Stevens, A. Olivárez, and D. Hamman, "The role of cognition, motivation, and emotion in explaining the mathematics achievement gap between Hispanic and White students," Hispanic Journal of Behavioral Sciences, vol. 28, no. 2, pp. 161-186, 2006

[18] E. L. Usher and F. Pajares, "Sources of academic and self-regulatory efficacy beliefs of entering middle school students," Contemporary Educational Psychology, vol. 31, no. 2, pp. 125-141, 2006, doi: 10.1016/j.cedpsych.2005.03.002.

[19] G. Joët, E. L. Usher, and P. Bressoux, "Sources of self-efficacy: An investigation of elementary school students in France," Journal of Educational Psychology, vol. 103, no. 3, pp. 649-663, 2011, doi: 10.1037/a0024048.

[20] R. W. Lent, F. G. Lopez, and K. J. Bieschke, "Mathematics self-efficacy: Sources and relation to science-based career choice," Journal of Counseling Psychology, vol. 38, no. 4, pp. 424-430. 1991.

[21] F. G. Lopez, R. W. Lent, S. D. Brown, and P. A. Gore, "Role of social-cognitive expectations in high school students' mathematics-related interest and performance," Journal of Counseling Psychology, vol. 44, no. 1, pp. 44-52, 1997.

[22] T. Stevens, K. Wang, A. Olivárez Jr, and D. Hamman, "Use of self-perspectives and their sources to predict the mathematics enrollment intentions of girls and boys," Sex Roles, vol. 56, no. 5-6, pp. 351-363, 2007, doi: 10.1007/s11199-006-9180-2.

[23] J. D. Dagdag, O. C. Anoling, Jr., R. P. Salviejo, and J. F. Pascual, "Development of problem-solving efficacy scales in mathematics," Universal Journal of Educational Research, vol. 8, no. 6, pp. 2397-2405, 2020, doi: 10.13189/ujer.2020.080624.

[24] R. M. Klassen, "A Cross-Cultural Investigation of the Efficacy Beliefs of South Asian Immigrant and Anglo Canadian Nonimmigrant Early Adolescents," Journal of Educational Psychology, vol. 96, no. 4, pp. 731-742, 2004.

[25] K. A. Gainor and R. W. Lent, "Social cognitive expectations and racial identity attitudes in predicting the math choice intentions of Black college students," Journal of Counseling Psychology, vol. 45, no. 4, pp. 403-413, 1998, doi: 10.1037/0022-0167.45.4.403.

[26] R. Özyürek, "Informative sources of math-related self efficacy expectations and their relationship with math-related self-efficacy, interest, and preference," International Journal of Psychology, vol. 40, no. 3, pp. 145-156, 2005, doi: $10.1080 / 00207590444000249$.

[27] N. Z. Hampton and E. Mason, "Learning disabilities, gender, sources of efficacy, self-efficacy beliefs, and academic achievement in high school students," Journal of School Psychology, vol. 41, no. 2, pp. 101-112, 2003, doi: 10.1016/S0022-4405(03)00028-1.

[28] A. Arslan, "Investigation of relationship between sources of self-efficacy beliefs of secondary school students and some variables," Kuram ve Uygulamada Eğitim Bilimleri, vol. 13, no. 4, pp. 1983-1993, 2013.

[29] J. W. Creswell and J. D. Creswell, Research Design: Qualitative, Quantitative, and Mixed Methods Approaches, 5th Ed. SAGE, 2018.

[30] M. Rahn, "Factor analysis: A short introduction, Part 5 - Dropping unimportant variables from your analysis," The Analysis Factor, 2008. [Online]. Available: https://www.theanalysisfactor.com/factor-analysis-5.

[31] J. Pallant, SPSS Survival Manual: A Step by Step to Data Analysis Using SPSS. New South Wales: Allen \& Unwin, 2011.

[32] G. F. Templeton, "A two-step approach for transforming continuous variables to normal: Implications and recommendations for IS research," Communications of the Association for Information Systems, vol. 28, no. 4, pp. 42-58, 2011, doi: 10.17705/1CAIS.02804.

[33] J. Pallant, SPSS survival manual: A step by step guide to data analysis using SPSS for windows, 3rd ed. McGrawHill, New York, USA, 2007.

[34] Y. Capa-Aydin, E. Uzuntiryaki-Kondakci, and R. Ceylandag, "The relationship between vicarious experience, social persuasion, physiological state, and chemistry self-efficacy: The role of mastery experience as a mediator," Psychology in the Schools, vol. 55, no. 10, pp. 1224-1238, 2018, doi:10.1002/pits.22201. 